\title{
Some Implications of Using Prices to Measure Productivity in a Two-Sector Growth Model
}

\author{
Milton Marquis \\ Federal Reserve Bank of San Francisco and Florida State University \\ and \\ Bharat Trehan* \\ Federal Reserve Bank of San Francisco
}

Revised: July 2003

\begin{abstract}
A two-sector growth model is used to study U.S. productivity growth since the 1960s. Sector-specific measures of productivity are constructed by imposing theoretical restrictions from this model on data on factor prices and the relative price of capital. Under the identifying restriction that capital-specific productivity growth be orthogonal to economy-wide productivity growth, shifts in TFP growth can be explained in terms of an economy-wide productivity growth slowdown in the mid-1970s and an acceleration in productivity growth in the capital goods sector in the mid-1990s. Also, interpreting changes in the relative price of capital as capital-specific technological change implies a theoretical restriction on the productivity processes that is rejected by our data.
\end{abstract}

JEL Classification: O40

Keywords: Productivity, technological change

\footnotetext{
${ }^{*}$ We would like to thank John Fernald, Tom Sargent, Carl Walsh and participants at seminars at U.C. Davis and the Federal Reserve Bank of San Francisco for helpful comments and discussions, as well as Tatiana Balekha for research assistance. Any opinions expressed in this paper are those of the authors and not those of the Federal Reserve System.
} 


\section{Introduction}

U.S. economic growth accelerated sharply in the second half of the 1990s, as did the rate of productivity growth. A notable feature was the surge in the output of information technology equipment, accompanied by a sharp fall in the relative price of such equipment. This has led some to herald the arrival of "a new economy." While it is hard to deny the impact of information technology on the economy, it is also useful to keep in mind that neither technological change nor rapid productivity growth are new phenomena. The 1960s, for instance, are well known as a period of rapid productivity growth. Thus, in thinking about recent developments, it is natural to ask whether the productivity growth in the late 1990s can be traced to the same forces that were behind the surge in productivity during the 1960s.

A look at the data in Figure 1 shows that the decline in the relative price of capital is not a new phenomenon either. ${ }^{1}$ In a recent, influential paper, Greenwood, Hercowitz and Krusell (GHK, 1997) explicitly identify the decline in the relative price of capital with capital-specific productivity growth in a one-sector neoclassical model and conclude that about 60 percent of the growth in U.S. productivity over the 1950 to 1990 period can be attributed to capital-specific technological change. In this paper we follow GHK, in that the relative price of capital is a key variable in our analysis, but conduct this analysis using a two-sector model that is similar to Whelan (2001).

We begin by constructing a theoretical model that contains two sectors: a final goods sector and a capital goods sector. Households derive utility from consuming the output of the final goods sector, the services from their stock of consumer durables - which are produced by the capital goods sector - and leisure. In addition, the capital goods sector produces capital goods that are used, together with labor, by both sectors to produce output. GHK have shown that a two sector model such as the one below can be represented as a one sector model provided certain assumptions (such as common factor shares in the production function

\footnotetext{
${ }^{1}$ In Figure 1, capital goods are defined as the sum of producer durable equipment and consumer durables; the details are in section 3 below.
} 
across sectors) are satisfied. We show that GHK's aggregation also imposes a restriction on the productivity processes in the two sectors, whose implications turn out to be important for the empirical analysis discussed below.

The two-sector model leads to restrictions on the relationship between productivity growth and factor prices and the relative price of capital goods. For the empirical analysis, we impose these restrictions on price data to compute the implied TFP in each sector, rather than attempting to construct Solow-like residuals from stock and flow quantity data on factor inputs and sectoral outputs. Our measures are similar to the one developed by Jorgenson and Griliches (1967) for a one-sector model and employed, among others, by Oliner and Sichel (2000) and Hsieh (2002). Since price- and quantity-based measures of productivity are dual to each other, we aggregate our sectoral TFP series to construct an economy-wide measure of total factor productivity and compare it to the measure of multifactor productivity constructed by the Bureau of Labor Statistics. Given the very different ways in which they are constructed, the two measures turn out to be close.

Because of our interest in recent developments in the capital goods sector, we next impose an identification scheme that decomposes our two productivity series into two orthogonal components: one that affects both sectors (which we call the economy-wide productivity process) and another that affects the capital goods sector alone. A statistical procedure developed by Bai and Perron (1998) is used to assess whether the secular behavior of the two measures has changed over time. The results reveal a significant downward shift in the growth rate of economywide productivity in 1976 (though the exact date is rather imprecisely estimated). In addition, there is strong evidence of an upward shift in the growth rate of productivity in the capital goods sector in the beginning of 1996 - and no evidence of any other shift. These results are consistent with the view that productivity improvements in the production of consumer and producer durables were largely responsible for the productivity boom of the late 1990s. We also show that equating the relative price of capital with capital-specific technical progress (as is done by GHK and other authors in subsequent papers) identifies a process for productiv- 
ity growth in the capital goods sector that is not orthogonal to the economy-wide productivity process in our sample of postwar U.S. data. Specifically, our results imply that, under this identification scheme, periods during which economy-wide productivity slows down (such as the 1970s) will appear also to be periods in which capital-specific productivity growth picks up.

Finally, we use the model's equilibrium conditions together with our measures of technological progress in the two sectors and the break dates identified in the data to obtain theoretical predictions of the relative growth rates of output across the two sectors. These are shown to compare favorably with U.S. data. Based on these results, we conclude that even though the rate of growth of final goods output in the second half of the 1990s was comparable to the 1960s, the source of growth was very different. Specifically, the high growth rates of the 1960s reflected rapid growth in economy-wide productivity, whereas the high growth rates of the late 1990s largely reflect productivity growth in the capital goods sector.

\section{A Two-sector Model}

A two-sector theoretical model is developed in this section with sector-specific technological progress. One sector produces final goods, from which households derive utility. The other sector produces capital goods that are used by both sectors as factor inputs in production and as consumer durables that provide utility to households through a stream of consumption service flows. In this model, the rate of growth of the relative price of capital goods to final goods reflects the different rates of technological progress between the two sectors, but includes economy-wide technological progress that may have differential effects on productivity across sectors. This differential effect of economy-wide technological progress must be identified in order to describe the separate contribution that capital- or investment-specific technological progress makes to aggregate productivity growth. As mentioned above, GHK have examined a single-sector version of a similar model with identical factor shares in production across sectors, based 
on which they intrepret the secular movement in the relative price of capital goods to final goods as measuring investment-specific technological progress. We compare the two models below.

\subsection{Households}

The economy is populated by a large number of identical households that maximize lifetime utility by choosing optimal paths for consumption bundles, investment portfolios, and time allocations, or:

$$
\max _{\left\{c^{n}(t), c^{d}(t), x^{d}(t), x^{f}(t), x^{c}(t), n^{f}(t), n^{c}(t), l(t)\right\}} \int_{t=0}^{\infty} e^{-\rho t}\left[c^{n}(t)+\eta_{1} c^{d}(t)+\eta_{2} l(t)\right] d t, \eta_{1}, \eta_{2}>0
$$

where the instantaneous utility function is log-linear in the consumption of final goods, $c^{n}(t)$, consumption service flows from the stock of consumer durables, $c^{d}(t)$, and leisure, $l(t)$. The household's subjective discount rate is denoted by $\rho \in(0,1)$. The household provides labor to both the capital goods firms in the amount $n^{c}(t)$, and to the final goods firms in the amount $n^{f}(t)$, and owns the economy's capital stock comprised of consumer durables, $k^{d}(t)$, as well as productive capital in the capital goods sector, $k^{c}(t)$, and in the final goods sector, $k^{f}(t)$. The corresponding gross investments in the capital stocks are denoted by $x^{d}(t), x^{c}(t)$, and $x^{f}(t)$, respectively.

The household faces a budget constraint:

$c^{n}(t)+q(t)\left[x^{d}(t)+x^{f}(t)+x^{c}(t)\right] \leq w(t)\left[n^{f}(t)+n^{c}(t)\right]+q(t) r(t)\left[k^{f}(t)+k^{c}(t)\right]$

where the wage rate, $w(t)$, and the unit price of capital goods, $q(t)$, are both expressed in units of final goods, and where $r(t)$ is the real rental rate on capital. The household therefore receives labor income, the first term on the right-hand side of equation (2), and rental income, the second term. Expenditures are for the purchase of final goods, the first term on the left-hand side, and for capital 
goods, the second term, where gross investments determine the rates of capital accumulation:

$$
\frac{d k^{i}(t)}{d t}=x^{i}(t)-\delta k^{i}(t)
$$

where $i=f, c, d$ assuming that all capital stocks depreciate at the same rate $\delta \in$ $(0,1)$.

Consumption service flows from the stock of consumer durables are assumed to be linear:

$$
c^{d}=\phi k^{d}, \phi>0
$$

The household also faces the usual nonnegativity and time resource constraints.

\subsection{Production Sectors}

The capital goods sector is assumed to be competitive and can be modeled as a single aggregate firm that maximizes profits by choosing its output, $x(t)$, and its factor inputs of capital, $k^{c}(t)$, and labor, $n^{c}(t)$, or:

$$
\max _{\left\{x(t), n^{c}(t), k^{c}(t)\right\}} q(t) x(t)-w(t) n^{c}(t)-q(t) r(t) k^{c}(t)
$$

subject to its Cobb-Douglas production technology:

$$
x(t) \leq \mu(t) k^{c}(t)^{\alpha} n^{c}(t)^{1-\alpha}, \alpha \in(0,1)
$$

Total factor productivity (TFP) in this sector grows exogenously as determined by the evolution of $\mu(t)$, whose growth rate we denote by $g_{\mu}$.

First-order conditions determine factor prices as functions of the relative price of capital to final goods, the firm's TFP, and the marginal products of capital and labor. 


$$
\begin{gathered}
w(t)=q(t) \mu(t)(1-\alpha)\left(k^{c} / n^{c}\right)^{\alpha} \\
r(t)=\mu(t) \alpha\left(k^{c} / n^{c}\right)^{\alpha-1}
\end{gathered}
$$

In a similar fashion, the final goods sector is also assumed to be competitive and chooses its output, $c^{n}(t)$, and factor employment decisions for capital and labor, $k^{f}(t)$ and $n^{f}(t)$, to maximize profits, or

$$
\max _{\left\{c^{n}(t), n^{f}(t), k^{f}(t)\right\}} c^{n}(t)-w(t) n^{f}(t)-q(t) r(t) k^{f}(t)
$$

subject to:

$$
c^{n}(t) \leq \theta(t) k^{f}(t)^{\alpha} n^{f}(t)^{1-\alpha}, \alpha \in(0,1)
$$

where $\theta(t)$ denotes exogenous technical progress and its growth rate is given by $g_{\theta}$.

As in the case of the capital goods sector, we obtain the following expressions for factor prices:

$$
\begin{aligned}
& w(t)=\theta(t)(1-\alpha)\left(k^{f} / n^{f}\right)^{\alpha} \\
& q(t) r(t)=\theta(t) \alpha\left(k^{f} / n^{f}\right)^{\alpha-1}
\end{aligned}
$$

\subsection{Equilibrium}

The equilibrium that we examine is for stationary time allocations where $x(t)=$ $x^{f}(t)+x^{c}(t)+x^{d}(t)$ for which:

$$
\begin{gathered}
r=\rho+\delta+\frac{g_{\mu}}{1-\alpha} \\
\widehat{x}=\widehat{x^{f}}=\widehat{x^{c}}=\widehat{x^{d}}=\widehat{k^{f}}=\widehat{k^{c}}=\widehat{k^{d}}=\widehat{c^{d}}=\frac{g_{\mu}}{1-\alpha}
\end{gathered}
$$




$$
\begin{gathered}
\widehat{c^{n}}=\widehat{w}=g_{\theta}+\frac{\alpha}{1-\alpha} g_{\mu} \\
\widehat{q}=g_{\theta}-g_{\mu}
\end{gathered}
$$

Equation (13) expresses the steady-state real rental rate, $r$, in terms of the household's discount rate, $\rho$, the depreciation rate on capital, $\delta$, and the rate of technological progress in the capital goods sector, $g_{\mu}$, adjusted for the factor share on labor, $1-\alpha$. Along the balanced growth path, equation (14) indicates that the last term in the determination of the real rental rate from equation (13), $\frac{g_{\mu}}{1-\alpha}$, is simply the rate of growth of output from the capital goods sector, $\widehat{x}$. Equation (15) indicates that output growth in the final goods sector is determined by factor shares in production $(\alpha)$ and the growth in TFP in both sectors, i.e., $g_{\theta}$ and $g_{\mu}$. Equation (16) indicates that the percentage change in the relative price of capital goods to final goods is fully determined by the difference between the growth rates of TFP in the final goods sector, $g_{\theta}$, and the capital goods sector, $g_{\mu}$.

Note that if you were to follow GHK and add output from the two sectors using the production functions in equations (6) and (10), you obtain the GHK single-sector version of the model, where:

$$
c+q x=\theta k^{\alpha} n^{1-\alpha}
$$

with $q=\theta / \mu$. GHK attribute secular movements in $q$ to capital- or investmentspecific technological progress. However, from equation (16), this can only be true if $g_{\theta}$ (which they identify as the economy-wide technology shock) is orthogonal to changes in the relative price of capital goods to final goods, $\widehat{q}$. This is an empirically testable restriction that we examine below.

\section{Measures of Productivity}

We begin by using the first-order conditions from the production side of our model to derive theoretical expressions for the technology shocks in the two sectors in 
terms of factor prices and the relative price of the capital goods vis-a-vis final goods.

From the equations for wages and rental rates [that is, (7), (8), (11) and (12)] as well as the production technology specified in (6) and (10), the following expressions can be derived for the TFP (technology shocks) series, $\mu(t)$ and $\theta(t)$.

$$
\begin{aligned}
& \mu(t)=\left[\frac{w(t)}{q(t)(1-\alpha)}\right]^{1-\alpha}\left[\frac{r(t)}{\alpha}\right]^{\alpha} \\
& \theta(t)=\left[\frac{w(t)}{1-\alpha}\right]^{1-\alpha}\left[\frac{q(t) r(t)}{\alpha}\right]^{\alpha}
\end{aligned}
$$

These measures are reminiscent of the price-based measure developed by Jorgenson and Griliches (1967) — in the context of a one-sector model — who also pointed out that the quantity- and price-based measures of productivity are dual to each other. For future reference, also note that the relative price, $q(t)$, is given by the ratio of the technology shocks, $\theta(t) / \mu(t)$, or

$$
\widetilde{q}(t)=\widetilde{\theta}(t)-\widetilde{\mu}(t)
$$

where the tilde “ " represents natural logs, e.g., $\widetilde{q}(t)=\ln q(t)$.

\subsection{The Data}

We now describe how the empirical measures of output, wages, prices and real rates of return are constructed to match the theoretical concepts in the previous section. For the empirical counterpart of the output of final goods in the model, we use the output of consumer nondurables and services from the NIPA accounts. The output of capital goods in the model is matched with the output of consumer durables plus producer durable equipment in the NIPA accounts. The aggregation of consumer durables with producer durables follows Whelan (2001), who shows that over the postwar period the behavior of consumer durables (especially relative 
prices) looks much more like producer durables than consumer nondurables and services. $^{2}$

The relative price of capital is then defined as the price of consumer plus producer durables relative to the price of consumer nondurables plus services. Figure 1 plots this relative price over the 1959-2000 period. To get a measure of the real wage, the series on total compensation per hour in the business sector is deflated by the price index for consumer nondurables and services. The real rate of return on capital is proxied by a constructed measure of the real rate of interest. The results below are based on a measure which subtracts expected inflation from the interest rate on triple-A rated corporate bonds, where expected inflation is defined as a centered five-quarter moving average. To test the sensitivity of our results, we repeated much of the analysis with the 6-month commercial paper rate (instead of the triple-A corporate bond rate) as well as purely backward and forward looking measures of inflation. These changes made no material difference. An alternative would be to use a measure based on after-tax returns on capital, such as the one constructed by Poterba (1997); Cooley and Prescott (1995) suggest a similar measure. We decided against such a measure because it requires a capital stock series, which is only available at an annual frequency. However, as a robustness check on our results, we constructed annual $\theta_{t}$ and $\mu_{t}$ series for the 1959-1995 period using both Poterba's time series and the AAA bond rate used above (since Poterba's series end in 1995). The two TFP measures had correlations in levels of 0.996 and 0.999 , respectively, and correlations in growth rates of 0.953 and 0.932 , respectively; while the corresponding economy-wide productivity measures (described below) had correlations of 0.976 in levels and 0.956 in growth rates.

Finally, we also need a value for the one parameter that shows up in the equations for $\mu(t)$ and $\theta(t)$ above, which is capital's share of income, or $\alpha$. There is some debate about the exact value of this parameter. Here, we rely on recent work by Gollin (2002), and set $\alpha=.267$, which is the middle value of three es-

\footnotetext{
${ }^{2}$ Investment in structures is omitted from the analysis, since data reveal little evidence of capital-specific technological progress in that sector. The government sector is also omitted.
} 
timates he presents for the U.S. The key assumption underlying this estimate is that the ratio of labor income to total income in the noncorporate sector (which cannot be observed directly) is the same as it is in the corporate sector Two other assumptions made by Gollin with respect to the composition of the surplus in the noncorporate sector lead to values of $\alpha$ equalling 0.227 and 0.336. Below, we discuss how our estimates of productivity change when the value of $\alpha$ changes.

\subsection{The Empirical Measures}

Figure 2 shows our (discrete-time) measures of TFP obtained by using equations (18) and (19) over the 1959Q2-2000Q4 period. Productivity in the final goods sector $\left(\theta_{t}\right)$ is displayed in the top panel. It shows rapid growth through the $1960 \mathrm{~s}$ and early 1970s, but then declines somewhat over the second half of the sample. This pattern is similar to that reported by GHK (1997), though they interpret their variable as measuring productivity growth in the economy as a whole. Hornstein and Krusell (2000), however, offer a different interpretation, stating that GHK's measure isolates productivity in the consumption goods sector, instead of the aggregate economy. Under this interpretation, our measure and theirs' can be compared directly; the comparison suggests that the two measures are telling a reasonably consistent story about productivity in the (services and nondurables goods consumption or) final goods sector despite the very different ways in which they have been constructed.

Economy-wide productivity also depends upon productivity in the capital goods sector. Our measure of TFP in the capital goods sector $\left(\mu_{t}\right)$ is shown in the middle panel. It shows little evidence of a slowdown in the mid-1970s, but does suggest an acceleration towards the end of the sample. The bottom panel shows our measure of economy-wide productivity, which is constructed as a Divisia aggregate of productivity in the two sectors, following Whelan(2001). ${ }^{3}$

\footnotetext{
${ }^{3}$ Hulten(1973) provides a set of necessary and sufficient conditions under which the Divisia index is the "...best choice among index numbers.." in that it becomes path independent and thus retains all the information up to an arbitrary normalization of the aggregation problem.
} 
To provide a better sense of how our constructs compare to more conventional measures, Figure $3 \mathrm{~A}$ plots our measure of aggregate productivity together with the corresponding measure of multifactor productivity constructed by the Bureau of Labor Statistics (BLS). ${ }^{4}$ Given the very different ways in which these two series are constructed, they turn out to be reasonably close. Note also that our measure is less volatile than the BLS measure; for instance, it does not decline as sharply as the BLS measure does during the recessions in the mid-1970s and the early-1980s.

We now turn to the question of what happens to our measures of productivity when we change the value of $\alpha$ that is used to construct these measures. Profitmaximizing conditions in the capital goods sector imply that

$$
\Delta \ln \left(\frac{w_{t}}{q_{t}}\right)=\frac{\Delta \widetilde{\mu}_{t}}{1-\alpha}
$$

Thus, given the historical realizations of $w$ and $q$ in the data, raising the value of $\alpha$ will lead to a decline in the estimate of $\Delta \widetilde{\mu}_{t}$ at each point in time, since the ratio of this term to $(1-\alpha)$ is fixed by the data. Further, (16) implies that any change in the estimate of $\Delta \widetilde{\mu}_{t}$ will lead to an equal change in the estimate of $\Delta \widetilde{\theta}_{t}$ (once again because $q_{t}$ is given). To provide a sense of how much difference this makes in practice, Figure 3B plots the BLS measure relative to the two other values of $\alpha$ from Gollin(2002), specifically, $\alpha=0.227$ (labelled low-alpha) and $\alpha=0.336$ (labelled high-alpha). A comparison of the two price-based measures reveals that a higher value of $\alpha$ tends to flatten the estimate of productivity growth, consistent with the discussion above. The high-alpha line shows little growth, on net, over the second half of our sample. The low-alpha line produces a growth rate estimate over the full sample that is closer to the growth rate of the BLS estimate than the original value shown in Chart $3 \mathrm{~A}$, as evidenced by the fact that the low-alpha measure lies closer to the BLS measure both at the beginning and

\footnotetext{
${ }^{4}$ The BLS measure of productivity, as well as notes on its construction, is available on the website: http://www.bls.gov/news.release/prod3.toc.htm. These data are annual and were only available through 2000 as of June 2002. To plot them at a quarterly frequency, we have used an interpolation routine from RATS. To make them easier to compare, all series have been normalized to equal 100 in 1980 Q1.
} 
at the end of the sample. Nevertheless, we stay with our original estimate of $\alpha$ in what follows, because we prefer the underlying assumption about noncorporate sector income.

\subsection{Identification}

In deriving our measures of total factor productivity growth we have imposed no restrictions on the relationship between productivity growth in the two sectors. In principle, long-run changes in the two series could be the result of one or more common factors. Alternatively, at the other extreme, the two series could evolve more or less independently of each other in the long run. In practice, the two series $\widetilde{\theta}_{t}$ and $\widetilde{\mu}_{t}$ turn out to have a correlation of 0.61 . When first-differenced, the correlation between the two series is 0.48 , which is still relatively high. Given these magnitudes, it is natural to wonder about the sector-specific components of these series; for instance, how much of the increase in productivity in the capital goods sector can be attributed to developments in the capital goods sector alone, and how much is due to economy-wide changes? To answer such questions, we need to impose some further structure on the relationship between the two series.

We begin by examining the time series properties of our productivity measures. As Figure 2 suggests, both series turn out to be nonstationary, even after we allow for a linear trend. When $\widetilde{\mu}_{t}$ is regressed on one lag plus a trend, the coefficient on the lag term exceeds one. The same regression for $\widetilde{\theta}_{t}$ leads to a coefficient that is less than 1 , but a Dickey-Fuller statistic of -1.4 , which is quite a bit smaller (in absolute terms) than the 5 percent critical value of -3.5 . The augmented Dickey-Fuller test gives similar results. Thus, we cannot reject a unit root in either process. The two series turn out not to be cointegrated either. For instance, when the Dickey-Fuller test is applied to the residual from a regression of $\widetilde{\mu}_{t}$ on $\widetilde{\theta}_{t}$, we get a Dickey-Fuller test statistic of $1.5 .^{5}$ A finding of cointegration would have implied that long-term productivity growth in both sectors was driven by a common trend, so that the levels of productivity in the two sectors would tend to

\footnotetext{
${ }^{5}$ For a discussion of various tests for unit roots and cointegration, see Maddala and Kim (1998).
} 
remain close to one another. However, our finding suggests that the two levels can drift apart with separate trends, implying that $g_{\mu} \neq g_{\theta}$. We therefore allow for this feature in the time series by working with log-differences only in what follows.

What sort of structure should we impose on the relationship between these two series? Given our interest in recent developments in the IT sector (which is part of the capital goods sector here), we are interested in decompositions that isolate shocks that are specific to the capital goods sector. Accordingly, we assume that there is one shock that is common to both sectors, while the second shock hits the capital goods sector alone. In other words, $\widetilde{\theta}_{t}$ will have the interpretation of an economy-wide shock to productivity, while the second component will be sectorspecific.

We impose orthogonality on our two components by regressing $\Delta \widetilde{\mu}_{t}$ on $\Delta \widetilde{\theta}_{t}$ and identifying the residual with the sector-specific component $\Delta \widetilde{\mu}_{t}^{r}$. More specifically, we postulate that :

$$
\Delta \widetilde{\mu}_{t}=a \Delta \widetilde{\theta}_{t}+\Delta \widetilde{\mu}_{t}^{r}
$$

implying that $\Delta \widetilde{q}_{t}=(1-a) \Delta \widetilde{\theta}_{t}-\Delta \widetilde{\mu}_{t}^{r}$. One advantage of this specification is that it does not preclude the economy-wide shock from having an effect on the relative price of capital goods. Note, in particular, that the relative price of capital goods could even fall in response to the economy-wide shock - if $a$ were to turn out to be larger than 1. That is, if the common shock had a larger impact on the capital goods sector than on the final goods sector, the relative price of the capital good would fall in response to positive shocks of either kind.

Note also that restricting $a$ to equal 1 in (21) gives us an alternate measure of technological progress in the capital goods sector:

$$
\Delta \widetilde{\mu}_{t}=\Delta \widetilde{\theta}_{t}+\Delta \widetilde{\mu}_{t}^{r}
$$

This relation, together with the condition that $\Delta \widetilde{q}_{t}=\Delta \widetilde{\theta}_{t}-\Delta \widetilde{\mu}_{t}^{r}$ (see equation (20)) implies $\Delta \widetilde{q}_{t}=-\Delta \widetilde{\mu}_{t}^{r}$. Thus, if the economy-wide shock has the same impact on the capital and final goods sectors, the change in the relative price of 
the capital good is exactly equal to the negative of the productivity shock that is specific to the capital goods sector, which is the identification imposed by GHK(1997).

We estimate equation (21) after including a constant, and obtain

$$
\Delta \widetilde{\mu}_{t}=\underset{(19.1)}{0.0065}+\underset{(5.2)}{0.34} \Delta \widetilde{\theta}_{t}
$$

where the t-statistics are shown in parentheses, and the equation has an adjusted $R^{2}=0.14$. The estimated value of $a=0.34$ implies that a one percent increase in economy-wide productivity raises $\widetilde{q}_{t}$ by about two-thirds of a percent. Note that the estimate of $\alpha$ is less than 1 at any conventional significance level. Thus, constructing a measure of capital-specific technical change by subtracting $\Delta \widetilde{\theta}_{t}$ from $\Delta \widetilde{\mu}_{t}$ will induce a negative correlation between this measure of capital-specific technical change and economy-wide technical change.

Figure 4 plots our estimates of $\Delta \widetilde{\theta}_{t}$ and $\Delta \widetilde{\mu}_{t}^{r}$. From the plot of $\Delta \widetilde{\theta}_{t}$ (see the top panel), the mean growth rate of economy-wide productivity appears to be somewhat higher in the early part of the sample; in the lower panel (which shows the growth rate of productivity in the capital goods sector), the sequence of positive shocks in the late 1990s is striking.

\subsection{Testing for Breaks}

We now carry out some formal tests to determine whether the behavior of our productivity measures has changed over time. Specifically, we ask whether the mean growth rates of productivity in the two sectors have shifted over our sample. To remain consistent with our theoretical derivations above, we will work under the maintained hypothesis that any breaks that occur are unexpected. The tests we employ are due to Bai and Perron $(1998)^{6}$. These tests allow for multiple breaks and can be used to detect breaks in the series when neither the dates nor the number of breaks are known.

\footnotetext{
${ }^{6} \mathrm{We}$ are grateful to Pierre Perron for providing us with a copy of his program to perform the calculations below.
} 
In testing for breaks, we drop 10 percent of the sample at either end; given a sample of 165 observations, this means that we effectively test for breaks over the dates from 1963:3 to 1996:4. Ten percent is also the size of our smallest interval in the tests below; in other words, two breaks cannot occur within 16 quarters of each other. We allow a maximum of 5 breaks over our sample in all of the tests that follow. The limit of 5 breaks is never binding in the sequential tests below.

We present the results from three different tests in Table 1, based on recommendations in Bai and Perron (2000). ${ }^{7}$ The first two columns (of data) present tests for - one or more - shifts in the mean growth rates of the orthogonal productivity processes identified above. The first column presents the results of regressing $\Delta \widetilde{\theta}_{t}$ (which equals the growth rate of TFP for the final goods sector, and which we identify as the economy-wide shock) on a constant and one lag. ${ }^{8}$ The first entry contains the results from BP's UDmax test, which tests the null hypothesis of no break against the alternative of an unspecified number of breaks (up to our maximum of 5 breaks). The null of no breaks is rejected at the 1 percent level; thus, there is at least one break in the series. Next, we present the results from BP's Sup(2|1) test, which tests the null of 1 break against the alternative of 2 breaks. The null hypothesis cannot be rejected at conventional significance levels. The next row shows the break date identified by this procedure, which turns out to be 1976:2. Finally the sequential procedure shows a break at 1976:2 which is significant at the 5 percent level; the procedure finds no other breaks at even the 10 percent level.

Using this break date, the estimated equation is:

$$
\Delta \widetilde{\theta}_{t}=\underset{(3.9)}{0.24} D_{1 t}^{\prime}-\underset{(-0.8)}{0.04} D_{2 t}^{\prime}+\underset{(3.3)}{0.25} \Delta \widetilde{\theta}_{t-1}
$$

where $D_{1 t}=1$ before 1976:2 and 0 over the rest of the sample while $D_{2 t}=0$

\footnotetext{
${ }^{7}$ According to Bai and Perron (BP), the sequential procedure works best overall, but often can be improved upon by a combination of the UDmax and the Sup(i+1|i) test. For that reason, we present results from all three tests.

${ }^{8}$ Here and in the other regressions in Table 1, lags of the dependent variable are only included if they are significant.
} 
before 1976:2 and 1 afterwards; t-statistics are shown in parentheses. Since the coefficients on the dummy variables have been multiplied by 100 , our estimates indicate that the economy-wide productivity component, $\Delta \widetilde{\theta}_{t}$, grew at approximately 1.3 percent per year before $1976: 2$ and was essentially flat after that. A nice feature of the BP procedure is that it gives us confidence intervals for the estimated break dates. The estimated intervals turn out to be rather wide here, with the $95 \%$ confidence interval stretching from 1972:1 to 1987:2 while the $90 \%$ interval extends from 1973:4 to $1984: 1 .{ }^{9}$

Column 2 presents the results of the same set of BP break tests for $\Delta \widetilde{\mu}_{t}^{r}$ (the capital-goods-sector productivity shock that is orthogonal to the economy-wide shock), where the regression contains one lag of the dependent variable. We find strong evidence of a single break at the beginning of 1996 as the statistics from both the UDmax and the sequential procedure are both significant at the 1 percent level. The estimated equation is

$$
\Delta \widetilde{\mu}_{t}^{r}=\underset{(-1.4)}{0.04} D D_{3 t}+\underset{(4.1)}{0.38} D D_{4 t}+\underset{(4.2)}{0.31} \Delta \widetilde{\mu}_{t-1}^{r}
$$

where $D D_{3 t}=1$ up to $1995: 4$ and is zero after that while $D D_{4 t}$ is zero up to the end of 1995 and equals one after that. According to our estimates the rate of productivity growth in the capital goods sector increased by more than two percent after 1995 (since the coefficients have been multiplied by 100). ${ }^{10}$ We obtain much tighter confidence intervals for the break dates this time. The $95 \%$ confidence interval is just a little more than two years wide, extending from 1995:3 to $1997: 4$, while the $90 \%$ interval spans about a year-and-a-half, from 1995:4 to 1997:1.

The third column of the table presents the results of break tests applied to $\Delta \widetilde{\mu}_{t}$, which measures total factor productivity growth in the capital goods sector. As is the case with $\Delta \widetilde{\mu}_{t}^{r}$, there is unambiguous evidence of a break in the $\Delta \widetilde{\mu}_{t}$ process

\footnotetext{
${ }^{9}$ Based on the results of a simulation study, Bai and Perron(2000) state that confidence intervals tend to be large when breaks are either"too small" or "too large."

${ }^{10}$ The negative coefficient on $D D_{3 t}$ reflects the fact that $\Delta \widetilde{\mu}_{t}^{r}$ is the residual from regression (23) and so sums to zero.
} 
in 1996:1, as the statistics from both the UDmax test and the sequential test are significant at the 1 percent level. Perhaps more interesting is the evidence of a second break in 1973:4, with the test statistic from the $\operatorname{Sup}(2 \mid 1)$ test significant at the 1 percent level while the Sequential test is significant at 5 percent. The estimated equation is

$$
\Delta \widetilde{\mu}_{t}=\underset{(14.5)}{0.78} D D_{5 t}+\underset{(11.8)}{0.51} D D_{6 t}+\underset{(13.0)}{1.12 D D_{4 t}}
$$

where $D D_{5 t}$ is a dummy variable that is zero everywhere except the period before 1974:1, $D D_{6 t}$ is a dummy variable that is one between 1974:1 and 1995:4, and zero everywhere else and $D D_{4 t}$ is as defined before. (Lags of the dependent variable were not included because they were insignificant.) Here, again, the confidence interval associated with the break in the 1970s is rather wide, with the 90 percent interval extending from 1966:3 to 1978:1. By contrast, the 90 percent interval associated with the break in the 1990s is only 11 quarters wide and extends from 1994:2 to 1997:1.

The finding of a second break in $\Delta \widetilde{\mu}_{t}$ but only one break in $\Delta \widetilde{\theta}_{t}$ and in $\Delta \widetilde{\mu}_{t}^{r}$ (where the date of the first break in $\Delta \widetilde{\mu}_{t}$ cannot be distinguished statistically from the date of the break in $\Delta \widetilde{\theta}_{t}$ ) provides support for the identification that we have imposed upon the data earlier. Consider, for example, the finding of a break in $\Delta \widetilde{\theta}_{t}$ during the 1970s. If this shock were not common to the two sectors (that is, productivity growth had not slowed down in both sectors), a regression of $\Delta \widetilde{\mu}_{t}$ on $\Delta \widetilde{\theta}_{t}$ would lead to a residual process $\left(\Delta \widetilde{\mu}_{t}^{r}\right)$ whose mean increased in the 1970s. Instead, we find no evidence of a break in $\Delta \widetilde{\mu}_{t}^{r}$ during this period, but do find evidence of a break in the $\Delta \widetilde{\mu}_{t}$ process (equation 26) at about the same time. In addition, the fact that the second break (during the 1990s) is unique to $\Delta \widetilde{\mu}_{t}^{r}$ argues against employing the reverse identification, which would be to identify $\Delta \widetilde{\mu}_{t}$ as the economy-wide shock and $\Delta \widetilde{\theta}_{t}^{r}$ as the shock specific to the final goods sector (where $\Delta \widetilde{\theta}_{t}^{r}$ would be the residual from a regression of $\Delta \widetilde{\theta}_{t}$ on $\Delta \widetilde{\mu}_{t}$ ). This is because the increase in the mean of $\Delta \widetilde{\mu}_{t}$ during this period would imply a decrease in the mean of $\Delta \widetilde{\theta}_{t}^{r}$ (since the mean of $\Delta \widetilde{\theta}_{t}$ did not change), which 
would amount to arguing that an increase in the mean growth rate of economywide productivity was exactly offset by a simultaneous-but independent-decrease in the mean growth rate of the productivity process which is unique to the final goods sector.

Before going on, it is useful to look at the measure of capital-specific productivity growth obtained by setting $a=1$ in equation (21) above. As mentioned earlier, this is the restriction required to equate the relative price of capital with capital-specific technical change, which in turn allows GHK and others to make inferences about the latter based on data for the former. Greenwood and Yorukoglu (1997), for instance, show that the rate of decline of the relative price of capital accelerated after 1974 and argue that this represents an acceleration in the pace of technical change in the capital goods sector that began in $1974 .{ }^{11}$

We denote the measure obtained by imposing this restriction by $\Delta \widetilde{\mu}_{t}^{g}$ and present the results of the break tests for this measure in column 4 of table 1 . The results are more ambiguous this time. The UDmax test rejects the null of no break at the 10 percent but not at the 5 percent level. The sup(2|1) test does reject the null of 1 break against the alternative of two breaks at the 5 percent level. The sequential procedure finds two breaks as well, but only at the 10 percent level. Accepting the finding of two breaks, the estimated equation is

$$
\Delta \widetilde{\mu}_{t}^{g}=\underset{(2.2)}{0.10 D} D D_{7 t}+\underset{(1.1)}{0.07} D D_{8 t}+\underset{(3.0)}{0.34 D} D D_{9 t}+\underset{(7.5)}{0.59} \Delta \widetilde{\mu}_{t-1}^{g}-\underset{(1.9)}{0.15} \Delta \widetilde{\mu}_{t-2}^{g}
$$

where $D D_{7 t}$ equals 1 before $1982 \mathrm{Q} 2$ and 0 after that, $D D_{8 t}$ equals 1 over 1982Q2 - 1995Q4 and zero everywhere else while $D D_{9 t}$ equals 1 after 1995Q4 and is zero everywhere else. It is also worth noting that the confidence intervals around the break dates shown in table 1 are very large. Specifically, the 90 percent interval around the first break covers the roughly 40 year period from 1958:1 to

\footnotetext{
${ }^{11}$ Others papers that have used the relative price variable to measure capital-specific technical change include Cummins and Violante (2002), Fisher(2002) and Krusell, Ohanian, Rios-Rull and Violante (2000).
} 
1997:4 while the 90 percent interval around the second break covers 30 quarters beginning in 1993Q4.

According to equation (27), capital-specific productivity growth increased by approximately 1.2 percent per year in mid-1982 and a further 2.5 percent per year at the end of 1995. Given the width of the confidence intervals around the first break, this increase in measured productivity in the capital goods sector could easily have taken place in the mid-1970s, which would make it consistent with the findings of Greenwood and Yorukoglu (1997). ${ }^{12}$ However, attaching such an interpretation to these results may not be as straightforward as it first appears to be. We begin by noting that there is no evidence of any acceleration in productivity prior to 1996 in the untransformed series (which is the TFP measure in the capital goods sector: $\Delta \widetilde{\mu}_{t}$ ). In fact, $\Delta \widetilde{\mu}_{t}$ slows down in the mid-1970s. Second, note that the results for an acceleration in capital-specific productivity are obtained by imposing the restriction that $a=1$ in (21) above, a restriction that is strongly rejected by the data (the associated $F(1,165)$ statistic has a value of 105). Since $a$ is, in fact, less than 1 in the data, we end up with a measure of capital-specific technological change that (instead of being orthogonal) is negatively correlated with the measure of economy-wide technological change. In particular, the growth rate of this measure of capital-sector technological change will rise whenever the growth rate of economy-wide technological change falls. This suggests that claims of an acceleration in capital-specific productivity growth - which are based on changes in the rate of decline of the relative price of capital — that is perceived to occur close to a period when economy-wide productivity growth slows down (such as the 1970s) need to be examined more carefully.

Overall, we interpret the results from this subsection as saying that there is strong evidence for one break in the process for economy-wide productivity growth, $\Delta \widetilde{\theta}_{t}$, around the mid-1970s and for a break in the capital-specific productivity growth process, $\Delta \widetilde{\mu}_{t}^{r}$, around the mid-1990s. While we are unaware of analyses that have tried to explain changes in average U.S. productivity growth

\footnotetext{
${ }^{12}$ Their sample ends before the second break date identified in this paper.
} 
over this entire period in a unified framework such as ours, the break dates we obtain are not out of line with dates that have been identified by other researchers. For instance, the estimated intervals for the $\Delta \widetilde{\theta}_{t}$ break date encompass the early 1970s, which is where many of the papers in the NBER(2001) volume on productivity analysis place the beginning of an extended period of slower productivity growth. Note, however, that these papers do not test for the date at which the break occurred. Our finding of a break in the $\Delta \widetilde{\mu}_{t}^{r}$ process at the end of 1995 is similar to Jorgenson's (2001) finding of a growth resurgence in the U.S. beginning in 1995, which he links to information technology in general, and to a shift in the product cycle for semiconductors, in particular ${ }^{13}$. Using data over the 1947-2000 period, Hansen (2001) finds evidence of a break in labor productivity (that is, output per hour) in durable goods manufacturing during the 1990s (with a point estimate of 1997). Similarly, Oliner and Sichel (2000), in a study that measures the contribution of computers to the recent surge in output and productivity growth, also locate the change in the middle of the 1990s, by comparing data up to 1995 with subsequent data; they also present data from some other papers that adopt the same break date.

Given this interpretation, Table 2 presents data on various measures of average productivity growth over the different subsamples. The first row of data shows that the mean growth rate of economy-wide productivity slowed in the mid-1970s, and has not picked up since. The second row presents data on $\Delta \widetilde{\mu}_{t}^{r}$, which grew at a mean annual rate of roughly 2.3 percent over the first two sub-samples, and at roughly double that rate over the last five years of the sample. The results in the third row present the projected value of total productivity growth in the capital goods sector (which we denote $\Delta \widetilde{\mu}_{t}^{P}$ ) based on the regression coefficients in equation (23) and the mean growth rates of $\Delta \widetilde{\theta}_{t}$ and $\Delta \widetilde{\mu}_{t}^{r}$ over the relevant subsample. These estimates show that productivity growth in the capital sector slowed down in the mid-1970s because economy-wide productivity growth slowed down, but

\footnotetext{
${ }^{13}$ Jorgenson finds that developments outside the IT sector have also contributed to the acceleration in productivity since 1995 .
} 
picked up in the mid-1990s because of developments specific to the capital goods sector.

\subsection{Predicted vs Actual Output Growth}

In the previous section, time series for total factor productivity were constructed for the final goods sector and the capital goods sector that were based strictly on the price data and restrictions from the theoretical model. No quantity data were used. In this section, we use these series to generate predictions about output growth rates in the two sectors. It is possible to do this because, along the balanced growth path, the growth rates of TFP in the two sectors fully determine the growth rates of output from those sectors, as shown in equations (14) and (15). We would like to see how well these price-based TFP measures capture sectoral growth rates.

Once again, we divide our sample into three separate periods: 1959:2-1976:1, 1976:2-1995:4 and 1996:1-2000:4. For each of these periods, we have computed the growth rates of output from the final goods sector, $\widehat{c^{n}}$, and from the capital goods sector, $\widehat{x}$, and compared them with the actual growth rates of consumer nondurables and services, $\widehat{c^{n *}}$, and consumer and producer durables, $\widehat{x^{*}}$, respectively.

The results are reported in Table 3. Note that all figures reported in the table are normalized by the (quarterly) growth rate of output from the capital goods sector in the first period. Specifically, the actual growth rates were divided by $\widehat{x}_{1959: 2-1976: 1}=1.33$ and the predicted growth rates (derived from the price-based TFP measures) were divided by $\widehat{x}_{1959: 2-1976: 1}=0.92$.

Broadly speaking, the model does reasonably well in matching the relative growth rates of the two sectors in the initial period as well as the changes in the growth rates of capital-sector output over time, but produces too sharp a slowdown in the growth rate of final goods in the middle period. More specifically, both the actual data and the predictions from the model show final goods output growing at a rate that is about 60 percent of the rate of growth of capital goods output in the first period. The actual data indicate that the productivity slowdown during 
the 1976:2-1995:4 period coincided with declines in output growth in both sectors, with the quarterly growth rate of final goods falling by 23 percent from the 1959:21976:1 period, while the growth rate of capital goods fell by 13 percent. Using the price-based TFP measures, the theoretical model predicts a decline of 17 percent in the growth rate of capital goods, which is close to the actual decline, but a 70 percent drop in the growth rate of final goods, which is much sharper than the actual drop.

In the actual data, the rebound in productivity since 1995 is accompanied by a strong pickup in the growth rate of final goods to 35 percent over the 1976:21995:4 period (with the growth rate actually rising about 5 percent above its first period value), while the growth rate of capitals rises by 100 percent, and even exceeds the original growth rate by 75 percent. The theoretical model using pricebased TFP measures predicts an almost identical pattern for the growth rate of capital goods, with the final period's growth rate exceeding that of the first period by 70 percent. The growth rate of final goods rebounds strongly as well (by 135 percent), but still remains nearly 30 percent below the growth rate in the original period.

The results in Tables 2 and 3 lead us to interpret the surge in output in the latter part of our sample as follows: Even though the rate of final goods output accelerated noticeably in the second half of the 1990s to reach values comparable to those observed in the 1960s, the source of growth was very different from what it had been in the 1960s. Specifically, while the high growth (in final goods output) in the pre-1973 period was due to the high growth of economy-wide productivity, an acceleration in the growth rate of productivity specific to the capital goods sector appears to have played a larger role in the high growth period of the late 1990s. This evidence also underscores the importance of using a two-sector model, such as the one developed in this paper, in analyzing patterns of growth in the economy. 


\section{Conclusions}

The U.S. economy grew rapidly during the 1960s, but then entered a lengthy period characterized by a "productivity slowdown." This period appears to have ended in 1995 with a strong resurgence in productivity growth, reminiscent of the growth rates seen during the 1960s. In this paper, we chose to analyze these developments with the help of a two-sector model. As we have shown above, the use of a two-sector model is preferable to a one-sector model because the latter imposes restrictions on the underlying productivity processes that are inconsistent with postwar U.S. data.

After imposing theoretical restrictions from our two-sector model on the data for factor prices and the relative price of capital goods, we found evidence of two breaks in trend productivity over the 1959-2000 period. The first occurs in 1976, and can be attributed to an economy-wide shock that reduces TFP in both sectors. The second occurs in 1995, and can be attributed to a secular change in TFP in the capital goods sector alone. In our model, the latter shock affects output growth in both sectors through capital deepening, but has a greater effect on the production of capital goods. As shown in table 3, these theoretical predictions are consistent with U.S. data.

Thus, our analysis suggests that the acceleration in productivity growth during the second half of the 1990s does not quite represent a return to the regime that prevailed in the 1960s and early 1970s, in the sense that the slowdown in productivity in the mid-1970s represented a slowdown in the economy-wide rate of productivity growth, while the pickup since the mid-1990s seems to be concentrated in the capital goods sector. Of course, this is not to say that the rate of economy-wide productivity growth is unlikely to pick up in the near future. By the same token, our analysis makes no prediction about how long the high productivity growth in the capital sector will last. 


\section{References}

Bai, Jushan and Pierre Perron. 1998. "Estimating and Testing Linear Models with Multiple Structural Changes," Econometrica, January, pp. 47-78.

—. 2000. "Computation and Analysis of Multiple Structural Change Models." mimeo.

Cummins, Jason G. and Giovanni Violante. 2002. "Investment Specific Technical Change in the United States (1947-2000): Measurement and Macroeconomic Consequences," Review of Economic Dynamics, pp. 243-284.

Cooley, Thomas F. and Edward C. Prescott. 1995. "Economic Growth and Business Cycles," Ch. 1, in Frontiers in Business Cycle Research, ed. by Thomas F. Cooley. (Princeton:Princeton): 1-38.

Fisher, Jonas.2002. “Technology shocks matter," Working Paper Series WP-0214, Federal Reserve Bank of Chicago

Gollin, Douglas. 2002. "Getting Income Shares Right," Journal of Political Economy, vol 110, April, pp. 458-474.

Greenwood, Jeremy, Zvi Hercowitz, and Per Krusell. 1997. "Long-run Implications of Investment-Specific Technological Change," American Economic Review, vol. 87 , no. 3, June: 342-362.

Greenwood, Jeremy and Mehmet Yorukoglu. 1997. "1974," Carnegie-Rochester Conference Series on Public Policy, June 1997, pp. 49-96

Hansen, Bruce E. 2001. "The New Econometrics of Structural Change: Dating Breaks in U.S. Labor Productivity," The Journal of Economic Perspectives, Fall 2001, pp. 117-128. 
Hornstein, Andreas and Per Krusell. 2000. "The IT Revolution: Is It Evident in the Productivity Numbers?" Federal Reserve Bank of Richmond Economic Quarterly, Fall, pp. 49-78.

Hsieh, Chang-Tai. 2002. "What Explains the Industrial Revolution in East Asia? Evidence from Factor Markets, " American Economic Review June, pp. 502-526.

Hulten, Charles R. 1973. "Divisia Index Numbers," Econometrica, vol 41, no. 6, November, pp. 1017-1025.

Jorgenson, Dale W. 2001. "Information Technology and the U.S. Economy," American Economic Review, vol. 91, no.1, March: 1-32. and Zvi Griliches. 1967. "The Explanation of Productivity Change." The Review of Economic Studies 34 (July), pp. 249-283.

Krusell, Per, Lee Ohanian, Jose-Victor Rios-Rull and Giovanni Violante. “CapitalSkill Complementarity and Inequality: A Macroeconomic Analysis, Econometrica, September, pp. 1029-1054.

Maddala, G.S. and In-Moo Kim. 1998. Unit Roots, Cointegration and Structural Change. Cambridge: Cambridge University Press

NBER. 2001 New Developments in Productivity Analysis. edited by Hulten, Charles R., Edwin R. Dean, and Michael J. Harper. (Chicago:The University of Chicago Press).

Oliner, Stephen D. and Daniel E. Sichel. 2000. "The Resurgence of Growth in the Late 1990s: Is Information Technology the Story?” FEDS Working $\quad P a$ per 2000-20 (May).

Poterba, James M. 1997. "The Rate of Return to Corporate Capital and Factor Shares: New Estimates Using Revised National Income Accounts and Capital Stock Data," National Bureau of Economic Research, Working Paper No. 6263. 
Whelan, Karl "Balanced Growth Revisited: A Two-Sector Model of Economic Growth," Federal Reserve Board Finance and Economics Discussion Series 200104. 


\section{Table 1: Testing for Productivity Breaks}

\section{Orthogonalized Processes}

Economy wide: Capital Sector:

Series tested:

$\Delta \widetilde{\mu}_{t}^{r}$
$36.9^{1}$

$4.2^{1}$

1996:1

Break dates-

from Sup tests

Break Dates-

from Sequential

Procedure

90\% Confidence

Intervals for

break dates

1976:2

1996:

$1976: 2^{5}$

1996: $1^{1}$

$73: 4-84: 1$

$95: 4-97: 1$
Other Measures of Capital

Sector Productivity

$\underline{\Delta \widetilde{\mu}_{t}} \quad \underline{\Delta \widetilde{\mu}_{t}^{g}}$

1996:1

1973:4

1995:4

1982:2

$1973: 4^{5}$

$1982: 2^{10}$

1996: $1^{1}$

$1995: 4^{10}$

66:3-78:1

58:1-97:4

94:2-97:1

93:4-01:1

Notes: ${ }^{1}$ denotes significant at $1 \%,{ }^{5}$ denotes significant at $5 \%,{ }^{10}$ denotes significant at $10 \%$. 


\section{Table 2: Productivity Growth Rates}

$\begin{array}{cccc} & 1959: 2-1976: 1 & 1976: 2-1995: 4 & 1996: 1-2000: 4 \\ \begin{array}{c}\text { Producitivity } \\ \text { Measure: } \\ \Delta \widetilde{\theta}_{t}\end{array} & 1.2 \% & -0.1 \% & -0.1 \% \\ \Delta \widetilde{\mu}_{t}^{r} & 2.3 \% & 2.3 \% & 4.7 \% \\ \Delta \widetilde{\mu}_{t}{ }^{P} & 2.7 \% & 2.3 \% & 4.6 \%\end{array}$

Table 3: Sectoral Output Growth

\begin{tabular}{cccccc} 
& \multicolumn{2}{c}{ Actual } & \multicolumn{2}{c}{ Predicted } \\
Period & $\widehat{c^{n *}}$ & $\widehat{x^{*}}$ & $\widehat{c^{n}}$ & $\widehat{x}$ \\
& & & & \\
1959:2-1976:1 & 0.62 & 1 & 0.58 & 1 \\
& & & & \\
1976:2-1995:4 & 0.48 & 0.87 & 0.17 & 0.83 \\
1996: $1-2000: 4$ & 0.65 & 1.75 & 0.40 & 1.70
\end{tabular}


Figure 1. The Relative Price of Capital Goods 1959 Q2 - 2000 Q4

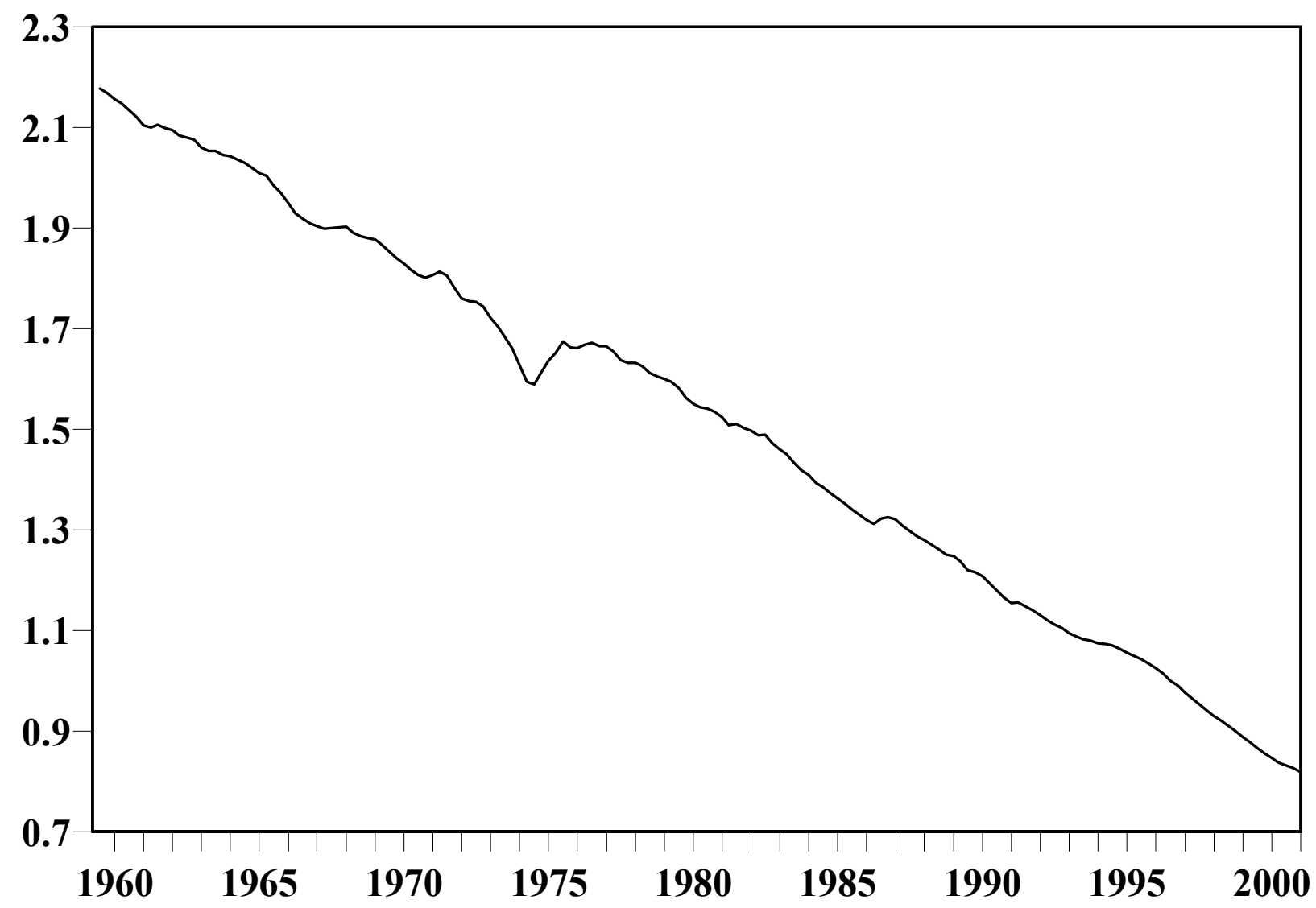


Figure 2. Measures of Productivity from a Two Sector Model 1959 Q2 - 2000 Q4*
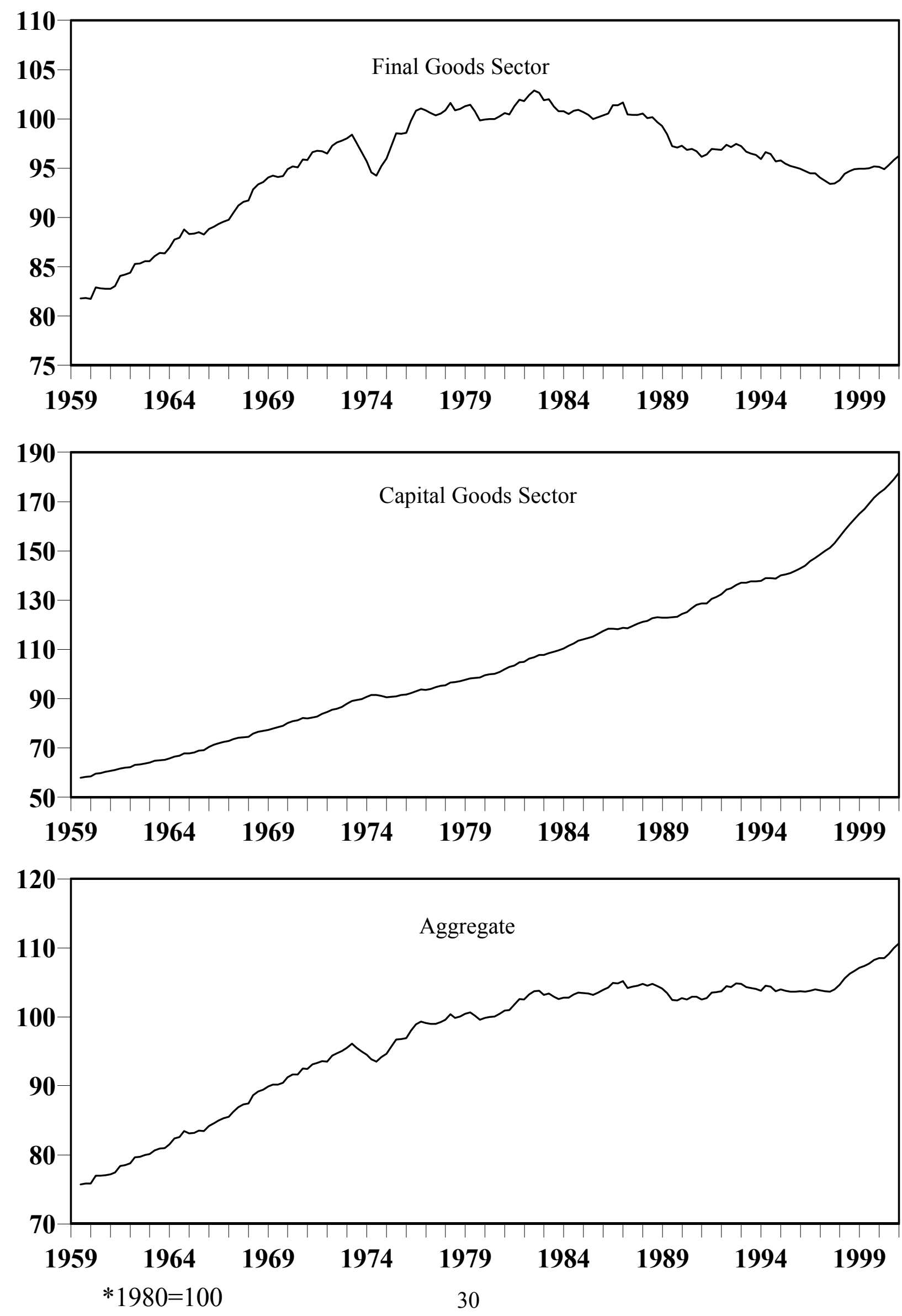
Figure 3. Alternative Measures of Aggregate Productivity*
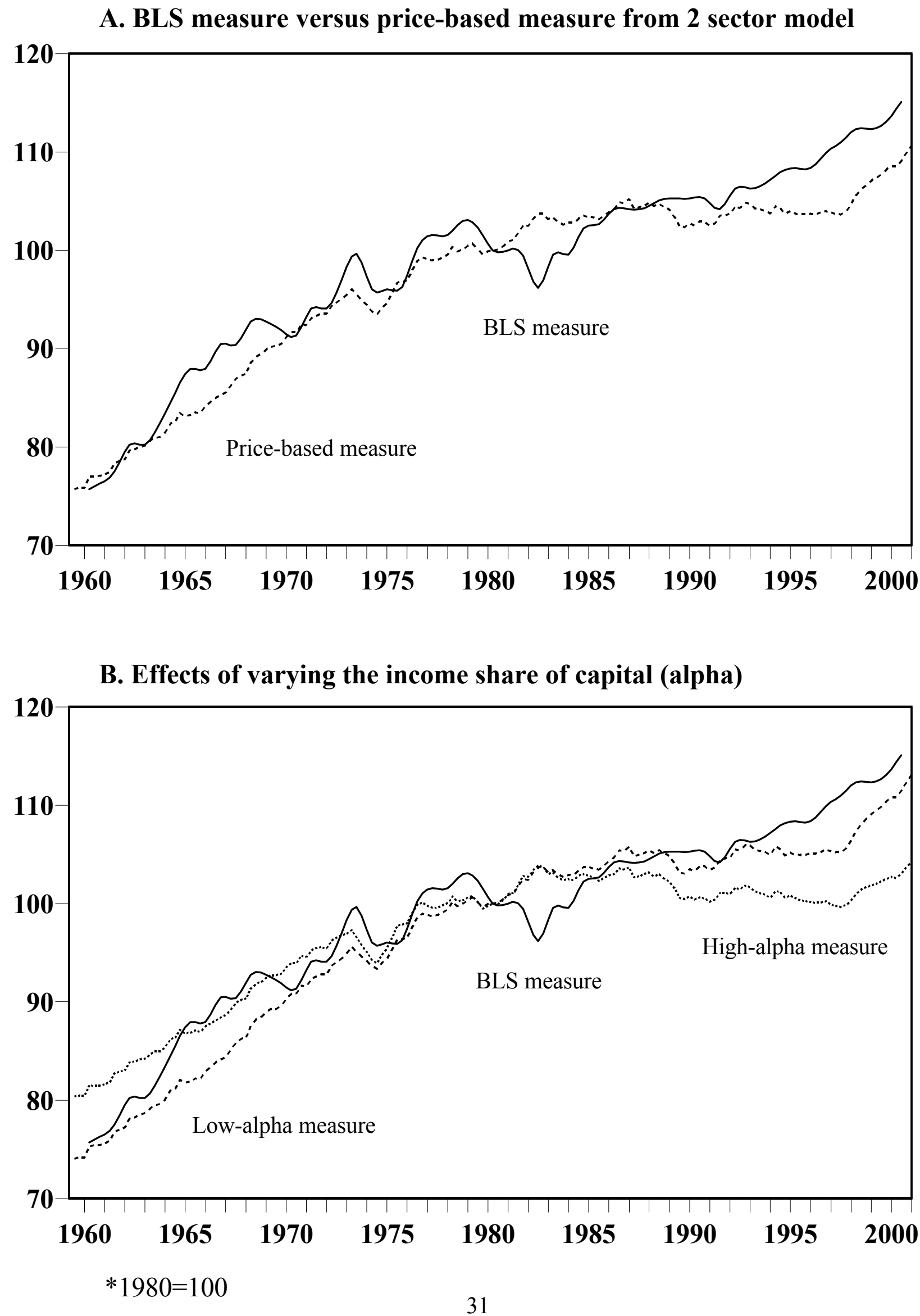
Figure 4. Orthogonal Measures of Productivity Growth
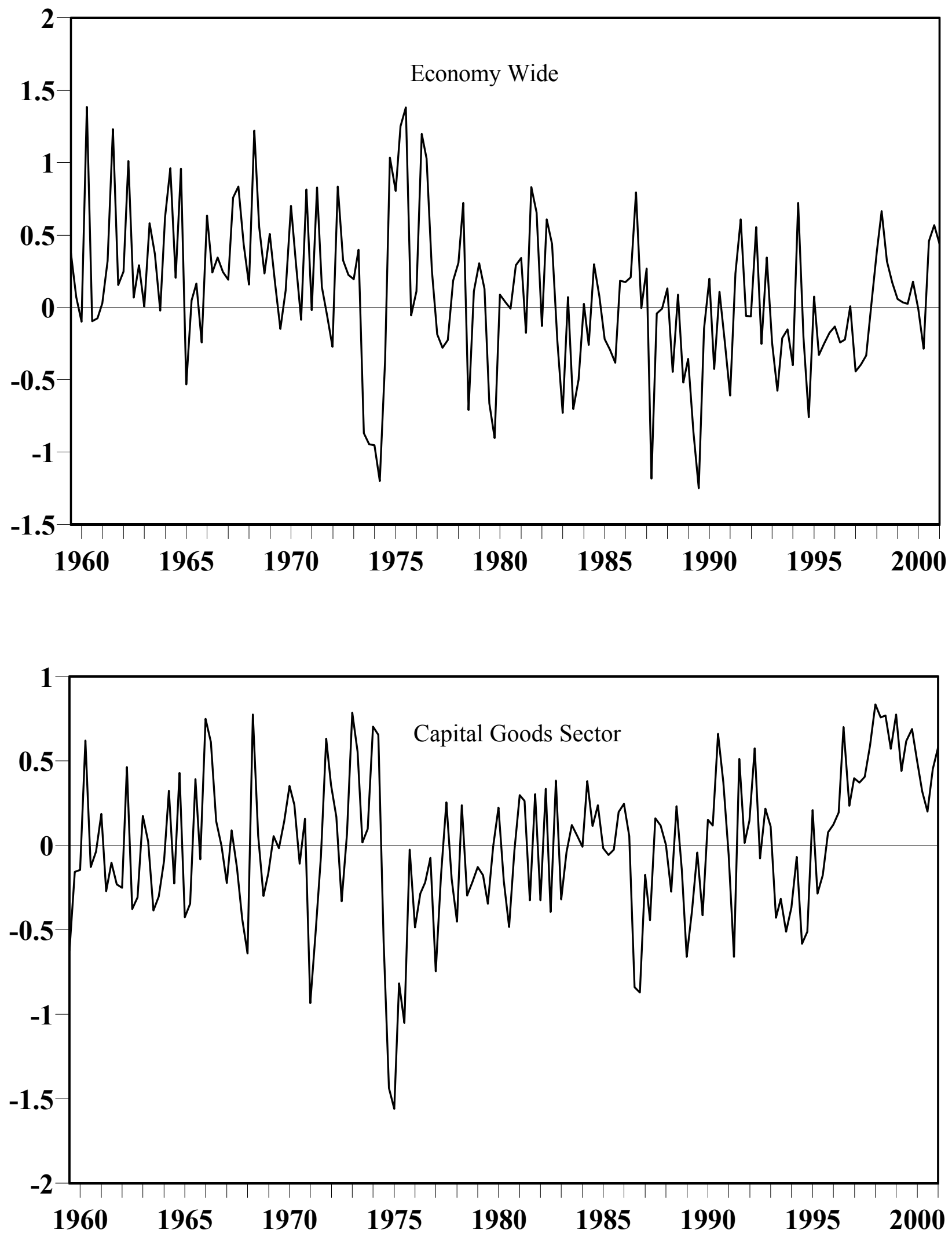